\title{
PODE O SUBALTERNO MAPEAR E INCIDIR NO PLANEJAMENTO REGIONAL? CONFLITOS TERRITORIAIS E DISPUTAS CARTOGRÁFICAS NO ORDENAMENTO FUNDIÁRIO DO OESTE DO PARÁ
}

\author{
Wendell Ficher Teixeira Assis* \\ * Universidade Federal de Alagoas, Instituto de Ciências Sociais - Programa de Pós-graduação em Sociologia, \\ Maceió, AL, Brasil.
}

\begin{abstract}
Resumo
$O$ ato de mapear é um exercício de poder que, simultaneamente, representa e nomeia o espaço. No intuito de elucidar como o aparato cartográfico tem sido utilizado em disputas territoriais, este artigo se dedica à análise do ordenamento fundiário conduzido pelo Governo do Pará no conjunto de glebas Mamuru-Arapiuns no final dos anos 2000. A ideia é compreender como se desenrolou a destinação de terras e analisar as formas de atuação das populações tradicionais e dos movimentos sociais na construção de uma proposta contra-hegemônica de uso e apropriação dos territórios. Ademais, busca-se entender como os mapas participativos são elaborados e utilizados nesse contexto de disputa territorial e cartográfica. Para tanto, lança-se mão de levantamentos bibliográficos e da realização de trabalhos de campo. As disputas materializadas nos mapas refletem um terreno onde o conflito se processa por meio da incomensurabilidade de interesses, por sua vez, orientados pela forma como a natureza é significada e utilizada material e simbolicamente.

Palavras-chave

Ordenamento fundiário; Mapeamento participativo; Disputa cartográfica; Luta territorial.
\end{abstract}




\title{
CAN THE SUBALTERN MAPPING AND FOCUS ON REGIONAL PLANNING? TERRITORIAL CONFLICTS AND CARTOGRAPHIC DISPUTES IN LAND REGULATING IN WESTERN PARÁ
}

\author{
Wendell Ficher Teixeira Assis* \\ * Universidade Federal de Alagoas, Instituto de Ciências Sociais - Post-Graduate Program on Sociology, Maceió, \\ AL, Brazil.
}

\begin{abstract}
The act of mapping is an exercise of power that simultaneously represents and names space. In order to elucidate how the cartographic apparatus has been used in territorial disputes, this article is dedicated to the analysis of the land planning conducted by the Government of Pará in the set of MamuruArapiuns plots in the late 2000 The idea is to understand how land allocation took place and to analyze the forms of action of traditional populations and social movements in the construction of a counter-hegemonic proposal for the use and appropriation of territories. Furthermore, it seeks to comprehend how participatory maps were developed and used in this context of territorial and cartographic disputes. To this end, bibliographic surveys and fieldwork are used. The disputes materialized on the maps reflect a terrain where the conflict takes place through the immeasurability of interests, in turn, guided by the way in which nature is signified and used materially and symbolically.
\end{abstract}

Keywords

Land planning; Participatory mapping; Cartographic dispute; Territorial struggle. 


\title{
PODE O SUBALTERNO MAPEAR E INCIDIR NO PLANEJAMENTO REGIONAL? CONFLITOS TERRITORIAIS E DISPUTAS CARTOGRÁFICAS NO ORDENAMENTO FUNDIÁRIO DO OESTE DO PARÁ
}

Wendell Ficher Teixeira Assis

\begin{abstract}
O que acontece se a língua culta tiver sido constituída ou for portadora de elementos venenosos? Palavras podem ser como minúsculas doses de arsênico: são engolidas de maneira despercebida e parecem ser inofensivas; passado um tempo, o efeito do veneno se faz notar. (KLEMPERER, 2009, p. 55).
\end{abstract}

Introdução

A história dos mapas está inextricavelmente conectada à ascensão dos Estados nacionais e ao estabelecimento do sistema de colônias, no qual mapear significava controlar territórios, criar identidades e legitimar novos domínios. Edney (2007) demonstra como o mapa de John Mitchell (Map of British and French Dominions in North America), de 1755, ao representar como de domínio britânico terras reivindicadas por colonizadores franceses, acabava por expressar um embate caracterizado pela rivalidade imperial, ao mesmo tempo que criava uma abstração que fazia frente às ameaças reais de ocupação das terras por parte dos franceses. Nessa mesma trilha, Pedley (2007) afirma que no século XVIII os conflitos entre as poderosas casas dos Habsburgo, Hanôver e Bourbon despertaram o apetite dos consumidores de mapas, de comandantes militares, ministros de governo e do público em geral, que acompanhavam o desenrolar das guerras por intermédio dos mapas, cujos conteúdos anunciavam os resultados de explorações e batalhas, além de propagandearem as descobertas de novas terras e de reservas de água.

Durante séculos, os Estados nacionais detiveram o monopólio na fabricação de representações cartográficas, e a elaboração dos mapas se efetivou como sinônimo de poder e dominação. No caso brasileiro, a produção de mapeamentos esteve historicamente atrelada a interesses estrangeiros: a ruptura democrática de 1964, por exemplo, foi alinhavada com uma autorização para que a aviação estadunidense realizasse um levantamento aerofotogramétrico de todo o território nacional, 
produzindo e retendo informações inéditas e de valor estratégico relativas ao espaço físico e à existência de recursos naturais (OLIVEIRA, 2013). Não obstante, a partir dos anos 1990 se disseminou mundialmente a execução de mapeamentos caracterizados como participativos, efetivados por organismos multilaterais e organizações da sociedade civil, como ONGs, fundações privadas, universidades, organizações indígenas e camponesas e movimentos sociais. Essa ressignificação do fazer/saber cartográfico pode ser, simultaneamente, vista como reflexo da crise de hegemonia do poder mapeador dos Estados e como fruto dos avanços tecnológicos que propiciaram uma redução nos custos dos mapas, o que facilitou sua apropriação por grupos sociais em situação de subalternidade. De todo modo, é preciso salientar o lugar ocupado pelas empresas de software, com suas patentes e direitos de propriedade intelectual; de maneira resoluta, elas se pronunciam exigindo o cumprimento de contratos de uso, capazes, em última instância, de reforçar novas formas de monopólio e minar a insurgência de grupos subalternos, agora não mais mediante iniciativas atreladas ao Estado, e sim às empresas privadas (ALMEIDA, 2013). Assim, a quebra na exclusividade de confecção dos mapas nos remete à instauração de um campo cartográfico, em que distintas racionalidades e visões de mundo se digladiam para impor legitimamente as linguagens, significações e representações que caracterizam os territórios e as relações de poder (BOURDIEU, 1989).

Para elucidar como o aparato cartográfico tem sido utilizado em disputas territoriais, este artigo se dedica à análise do ordenamento fundiário que foi conduzido pelo Governo do Pará, no conjunto de glebas denominado Mamuru-Arapiuns, localizado na região oeste do estado. A ideia é compreender como tem sido consolidada a destinação de terras nesse conjunto de glebas e analisar as formas de atuação das populações tradicionais e dos movimentos sociais na construção de uma proposta contra-hegemônica de uso e apropriação dos territórios. Além disso, tem-se a finalidade de entender como os mapas participativos foram elaborados e utilizados nesse contexto de disputa territorial e cartográfica.

Com esses objetivos, procedeu-se ao levantamento de material bibliográfico e à realização de uma pesquisa de campo conduzida no período de 12 de setembro de 2009 a 5 de outubro do mesmo ano, a qual foi e subdividida em três momentos. ${ }^{1}$ O primeiro, no município de Belém, teve como escopo captar as visões, os procedi-

\footnotetext{
1. Os trabalhos de campo tiveram como base a realização de entrevistas estruturadas e semiestruturadas, com registro em áudio e anotações no caderno de campo. Além disso, foram feitos registros etnográficos das visitas às comunidades ribeirinhas e da participação em reuniões, sempre utilizando a técnica da observação participante (MALINOWSKI, 1978). MALINOWSKI, B. A região e os habitantes do distrito do Kula. In: Os Argonautas do Pacífico Ocidental: um relato do empreendimento e da aventura dos nativos nos arquipélagos da Nova Guiné. São Paulo: Abril Cultural, 1978. p. 17-34.
} 
mentos e as práticas adotados pelos órgãos e institutos da administração paraense envolvidos no ordenamento territorial do conjunto de glebas Mamuru-Arapiuns, a saber: Instituto de Terras do Pará (Iterpa), Instituto de Desenvolvimento Florestal do Estado do Pará (Ideflor) e Secretaria Estadual do Meio Ambiente (Sema). A segunda fase foi desenvolvida no município de Santarém, no oeste do Pará, onde se intentou perceber as formas de organização social e as estratégias utilizadas por diferentes sujeitos que se aglutinaram para forjar um debate público acerca do processo de disputa territorial e de destinação das terras. Como desdobramento, lançou-se luz sobre o estabelecimento de alianças entre movimentos sociais, ONGs e órgãos da administração pública federal e estadual, com o propósito de elaborar um mapa participativo que buscava expressar as demandas das comunidades tradicionais, ao mesmo tempo que sinalizava para a constituição de um mosaico de usos naquele conjunto de glebas. Nesse sentido, foram entrevistados representantes das seguintes organizações e instituições: Sindicato de Trabalhadores e Trabalhadoras Rurais de Santarém (STTR); Comissão Pastoral da Terra (CPT); Federação das Organizações de Quilombolas de Santarém (FOQS); Pastoral Social, Ministério Público Estadual, Projeto Saúde e Alegria, Terra de Direitos, Conselho Nacional dos Seringueiros (CNS) e Instituto Brasileiro do Meio Ambiente e dos Recursos Naturais Renováveis (Ibama). Por fim, o estágio derradeiro foi realizado na Gleba Nova Olinda I, localizada nos municípios de Juruti e Santarém. Nessa fase, o objetivo foi captar as percepções que as populações tradicionais têm acerca do processo de ordenamento territorial, além de se compreender as formas de atuação e os embates ocorridos com permutados ${ }^{2}$, madeireiros e grileiros, que têm promovido um avanço acelerado da exploração florestal nessa região. Ademais, almejou-se desenovelar as tramas da participação comunitária nos processos de mapeamento, com o intento de examinar os dilemas, as imprevisibilidades e as conquistas que integram a construção desse instrumento cartográfico.

\footnotetext{
2. Durante o governo de Simão Jatene (2002-2006), autorizou-se, por meio do Decreto n. 2.472/2006, o assentamento na Gleba Nova Olinda I de empresários do Sul do país, chamados pelas instituições governamentais de permutados. Esses fazendeiros adquiriram títulos fundiários do Governo do Pará nos anos 1980 no âmbito do Projeto Integrado Trairão, desenvolvido pelo Iterpa no município de São Félix do Xingu. No entanto, em razão de essas terras serem secularmente ocupadas pelos índios Kayapó, a Fundação Nacional do Índio (Funai) determinou em 1990, por meio do Decreto n. 98.865/1990, que se tratava de uma área imemorialmente indígena e que se deveria proceder à imediata retirada dos ocupantes exógenos. Assim, em contrapartida, esses fazendeiros exigiram do governo paraense a indenização dos valores pagos ou a efetivação de um contrato de permuta para ocupação de uma nova área (BRASIL, 1990; ITERPA, 2009). BRASIL. Decreto-lei n. 98.865, de 23 de janeiro de 1990. Diário Oficial da União, 24/01/199o, p. 1715. Disponível em: https://www.planalto.gov.br/ccivil_03/decreto/1990-1994/d98865. htm. Acesso em: 27 out. 2009.
} 
A consideração dessas disputas cartográficas nos permite introduzir na análise dos mapas a incidência de diferentes atores, técnicas e ferramentas, bem como evidenciar as intencionalidades dos sujeitos e as formas de concretizá-las. Sobre esse aspecto, pode-se considerar que, na política dos mapeamentos, se estabelece uma disputa entre distintas representações do espaço; dito de outra forma, tem-se uma disputa cartográfica que se articula às próprias disputas territoriais (ACSELRAD; COLI, 2008). A cartografia tem, portanto, consequências políticas e instaura confrontos entre uma narrativa espacial que fortalece o discurso econômico e corrobora o alargamento de fronteiras operacionais à acumulação capitalista e outra que, alicerçada na insurreição de usos, elucida formas históricas de existência territorial e forja resistências às práticas hegemônicas. Em última instância, é necessário indagar o que ocorre quando redes de organizações e agências multilaterais recorrem ao conhecimento local produzido sobre o espaço; tais iniciativas podem tanto servir às estratégias de produção e controle sobre o território, incrementando o subjugamento, como podem fortalecer a construção de direitos territoriais e desestabilizar a dominação (ACSELRAD, 2013).

\section{Caracterizações do lugar/espaço e das disputas territoriais e cartográficas}

O complexo de glebas Mamuru-Arapiuns localiza-se na porção oeste do estado do Pará e se espraia pelos municípios de Aveiro, Santarém e Juruti, com limites, ao norte, com o rio Amazonas, ao sul com o Parque Nacional da Amazônia e com a Terra Indígena Andirá-Marau, a leste com a Reserva Extrativista Tapajós-Arapiuns e, a oeste, com o estado do Amazonas (Iterpa, 2009). Circundada por áreas protegidas de rica biodiversidade, com florestas que, em sua maior parte, apresentam baixa intensidade de supressão, essa é uma porção territorial cujo acesso é dificultado pela quase inexistência de vias terrestres; são os rios que exercem a função de principal forma de interligação entre as comunidades e as sedes municipais.

O conjunto Mamuru-Arapiuns é composto de cinco glebas estaduais denominadas Curumucuri, Nova Olinda I, Nova Olinda II, Nova Olinda III e Mamuru, cujo processo de destinação tem sido objeto de discussão entre o estado, movimentos sociais, empresários do agronegócio, populações tradicionais, permutados e madeireiros. É uma região historicamente ocupada por comunidades ribeirinhas, que, entretanto, têm sido alvo, desde o final da década de 1990, de intensa investida por parte de madeireiros e grileiros, oriundos tanto de zonas paraenses, onde a presença do Estado se efetivou por meio da criação de assentamentos, unidades de conservação e reservas extrativistas, como de outros estados da federação que possuem uma estrutura de fiscalização mais eficaz. As terras que compõem esse conjunto de glebas são matriculadas e arrecadadas em nome do estado do Pará 
e perfazem um total de 1,312 milhão de hectares de florestas contínuas, de grande importância no que se refere à preservação ambiental e à reprodução social de comunidades tradicionais. Não obstante, essas terras estão inseridas em uma região cuja dinâmica geoeconômica tem privilegiado a interligação de projetos hegemônicos de geração de riquezas, tais como a expansão de monocultivos de soja, sobretudo a partir de 2000, com a entrada em operação do porto da Cargil S/A em Santarém, o acirramento da grilagem e da especulação fundiária, impulsionados pela pavimentação da BR163 Cuiabá-Santarém, e a construção, em Juruti, de um complexo minerador operado pela Alcoa S/A. Ao se considerar somente o impacto da expansão da soja, há um incremento massivo na ocupação das terras no Pará, concentrando-se, notadamente, nas zonas de Santarém e Paragominas. Com isso, passou-se de 2,6 mil hectares na safra 1997-1998 para mais de 336 mil hectares em 2014-2015 (SAUER; MARTINS, 2016).

A existência dessas potencialidades econômicas tem desencadeado conflitos entre lógicas distintas de apropriação e uso do espaço: de um lado, populações tradicionais (ribeirinhos, seringueiros e indígenas3) lutam para garantir suas formas de reprodução social e de acesso aos recursos localizados no território e, de outro, madeireiros, empresários do agronegócio, permutados, mineradoras e grileiros vislumbram nessas terras uma possibilidade de expandir as fronteiras da acumulação capitalista e de mercantilização da natureza. Esse contexto de digladiação entre visões e práticas distintas é agravado pela assimetria de poder verificada entre os sujeitos sociais integrantes desse campo, bem como pelo histórico de presença débil das instituições e aparatos do Estado.

A despeito das demandas históricas de comunidades e movimentos sociais, durante a administração de Simão Jatene (2002-2006) teve início no conjunto de glebas Mamuru-Arapiuns, mormente na Gleba Nova Olinda I, um processo de ocupação e exploração madeireira orquestrado pelo Estado e alicerçado em dois instrumentos. De um lado, tem-se a concessão de Autorizações para Detenção de Imóveis Públicos (Adips) - um documento fundiário precário emitido em favor de madeireiros que afiança a exploração de recursos florestais em terras públicas, ao mesmo tempo que intensifica os conflitos territoriais - e, de outro, a celebração de escrituras públicas de permuta que garantem juridicamente o assentamento dos chamados permutados em terras tradicionalmente ocupadas por ribeirinhos, seringueiros e indígenas.

3. As comunidades de Novo Lugar, São José III e Cachoeira do Maró se autorreconhecem como indígenas e pleiteiam junto à Funai a demarcação da Terra Indígena Maró. 
Além de regulamentar a instalação dos permutados na Gleba Nova Olinda I, esse segundo instrumento estabelece como obrigação dos empresários a elaboração dos trabalhos de demarcação e georreferenciamento tanto das terras por eles ocupadas como dos territórios de domínio das populações tradicionais. O Estado transfere a uma parte diretamente interessada sua atribuição legal de mapear, acirrando ainda mais os conflitos e as tensões, sobretudo no que se refere à apropriação dos recursos florestais. A cláusula "h" do contrato de permuta, obtido durante o trabalho de campo, fixa que:

Fica ajustado[,] por meio deste instrumento, o compromisso dos permutantes [empresários] em assumir, em regime condominial, ou seja, com a contribuição e participação de todos os beneficiários da operação de permuta de que trata a presente escritura, todas as despesas que se fizerem necessárias à regularização das áreas efetivamente ocupadas pelas populações ribeirinhas tradicionalmente existentes ao entorno das terras permutadas, assim consideradas aquelas integrantes das quatorze comunidades já identificadas e cadastradas pelo Iterpa, inclusive quanto ao georreferenciamento de cada um dos lotes (Quarto Ofício de Notas de Belém, livro 156, p. 268, 2006).

Em entrevistas realizadas na aldeia de Novo Lugar, na Gleba Nova Olinda I, foi possível perceber que os indígenas identificam na figura dos permutados o vetor que norteia a chegada de novos grileiros. Por outro lado, eles consideram uma afronta à sua ocupação tradicional o fato de o Estado ter incumbido os empresários da execução do georreferenciamento, que, como não poderia deixar de ser, é instrumento fulcral para o procedimento de demarcação das terras.

Os permutados formam o caminho para a chegada de mais invasores. Eles começaram a fazer compra e venda de terras como se fossem os donos. O Ribamar [ex-comunitário de Fé em Deus que se associa aos permutados] e a Rondobel [empresa madeireira] foram fazendo venda de lotes aí dentro da Gleba Nova Olinda. O sofrimento chegou para nós porque aqui no final da terra indígena estamos limitando com grileiros e permutados. (Entrevista com liderança indígena M. Aldeia Novo Lugar, rio Maró, Gleba Nova Olinda I, 29 set. 2009.)

O georreferenciamento foi feito pela empresa madeireira. Chegaram aqui colocando os aparelhos sem nossa autorização. Fizeram uma verdadeira invasão, iam medindo e queriam logo sair sem dar nenhuma explicação do que estavam fazendo. Um dia meu avô se irritou com a presença de um deles que chegou aí na beira do rio, bem de frente da casa dele, e quis colocar um aparelho. Fomos até lá e dissemos que ali não iria colocar nada. A terra pode ser de proprie- 
dade do estado do Pará, mas nós somos os nativos daqui. (Entrevista com liderança indígena F. - Aldeia Novo Lugar, rio Maró, Gleba Nova Olinda I, 29 set. 2009.)

O Decreto n. 1.149/2008 do Governo do Pará, que instituiu a Área de Limitação Administrativa Provisória (Alap) Mamuru-Arapiuns, impediu o desempenho de atividades potencialmente poluidoras ou causadoras de degradação ambiental e vetou a continuidade daquelas que importassem em exploração a corte raso da floresta ou que implicassem o uso direto dos recursos naturais, excetuando a utilização sustentável realizada por comunidades tradicionais. Por intermédio desse instrumento legal, iniciava-se um esforço que objetivava ordenar o território, promover a retirada dos ocupantes ilegais e destinar terras às comunidades tradicionais do conjunto de glebas. Não obstante, a política de concessão florestal e de oferta de madeira tem se apresentado como real indutor do ordenamento territorial, como se pode inferir da entrevista realizada com a ex-presidente do Ideflor:

Quando a gente criou o Ideflor, havia uma pressão muito grande. Nós tínhamos o imperativo de ofertar madeira legal e nesse processo vimos que as glebas não destinadas, como é o caso do conjunto Mamuru-Arapiuns, eram as mais vulneráveis. Nesse cenário, a voracidade das ocupações ilegais exigia uma ação de Estado [...] decidimos [...] estudar a viabilidade técnica para fazermos a concessão florestal nessas glebas não destinadas e começamos o ordenamento territorial. [...] Nós necessitávamos apaziguar os conflitos e ofertar um primeiro lote de madeira legal. A concessão através do método que estamos utilizando ordena o território das comunidades ribeirinhas, cria unidades de proteção e o restante vai para as concessões florestais. As concessões são uma espécie de alavanca que sustenta o ordenamento. (Entrevista com a ex-presidente do Ideflor, Santarém, 1 out. 2009.)

É possível verificar, portanto, uma relação estreita entre o processo de ordenamento territorial em curso no conjunto de glebas Mamuru-Arapiuns e a consolidação da Lei de Gestão de Florestas Públicas, n. 11.284 (BRASIL, 2006), que regulamenta a exploração madeireira por intermédio de procedimentos de concessão florestal. Na primeira oferta pública do estado do Pará, concluída em 29 de setembro de 2011, foram assinados contratos com validade de trinta anos com a cessão de 150.956,9 hectares de florestas no conjunto de glebas Mamuru-Arapiuns (IDEFLOR-BIO, 2015). A exploração ficou a cargo de três madeireiras cujo histórico de atuação na região é considerado criminoso pelos comunitários. Para minimizar as tensões, os contratos preveem que a cada três anos, no mínimo, as empresas são obrigadas a realizar auditorias independentes conduzidas por profissionais 
creditados pelo Instituto de Metrologia, Qualidade e Tecnologia (Inmetro). No monitoramento ocorrido em 2016, foram detectadas graves irregularidades na operação das três concessionárias, com destaque para a ausência de monitoramento do transporte de madeira, a ausência de ações necessárias para consulta às comunidades, a ausência de técnicas adequadas para corte e derrubada de árvores, a exploração de espécies proibidas e o não atendimento às demandas das comunidades (SILVA; MELO JÚNIOR, 2018).

A promulgação da Lei n. 11.284/2006 é considerada um importante instrumento na política fundiária do Pará, principalmente por estabelecer em seu artigo $6^{\circ}$ que, antes da formalização das concessões florestais, as florestas públicas ocupadas ou utilizadas por comunidades locais serão identificadas para a destinação, pelos órgãos competentes, por meio da criação de reservas extrativistas e reservas de desenvolvimento sustentável, bem como mediante a cessão de uso levadas a cabo por projetos de assentamento florestal e de desenvolvimento sustentável, agroextrativistas ou similares (BRASIL, 2006). No entanto, a regularização fundiária dos territórios tradicionalmente ocupados pode ser vista como um mecanismo de dupla operação, uma vez que garante os direitos territoriais às populações tradicionais, ao mesmo tempo que titula, estabiliza e insere no mercado novas terras que são passíveis de serem incorporadas às frentes de acumulação do capital4. Na Gleba Nova Olinda I, a violência e a cooptação têm funcionado como mecanismos privados de apropriação de terras públicas, que operam por intermédio de ameaças de morte, oferecimento de regalias e intimidação às comunidades que se contrapõem à lógica predatória de madeireiros e grileiros. Nesse cenário de disputas, insurgem novos sujeitos políticos que acionam identidades étnicas e territoriais como forma de neutralizar os fluxos de expropriação dos territórios, enquanto simultaneamente intentam fortalecer a luta e tornar visíveis os conflitos derivados de práticas e visões distintas. A insubordinação desses sujeitos às categorias homogêneas incapazes de captar suas dinâmicas de ocupação territorial, em associação com suas afirmações de autorreconhecimento identitário, denota uma reação à brutalidade das frentes de expansão capitalista. Assim, essas novas formas de organização social têm funcionado como estratégias de disputa territorial,

\footnotetext{
4. Essa política de ordenamento territorial guarda algum paralelo com as estratégias verificadas por Oliveira Filho (1998) no extinto Serviço de Proteção aos Índios (SPI), em que, para acomodar o choque entre frentes de expansão econômica e grupos indígenas, se optava por estabelecer reservas com quantidade restrita de terras.
} 
as quais, ao se apropriarem de instrumentos jurídicos que reconhecem os direitos das populações tradicionais, aspiram a perpetuar suas formas de vida ${ }^{5}$.

Esses sujeitos espelham, entre outras coisas, novas estratégias de organização política que buscam forjar um cenário capaz de assegurar direitos territoriais a grupos sociais em situação de subalternidade. Em certa medida, no cerne desse fenômeno há uma interconexão entre autorreconhecimento identitário e luta por territórios, tendo como resultante uma nova vontade política que demanda do Estado reconhecimento social e jurídico. Nesse contexto, como argumenta Offen (2009), os mapeamentos participativos com povos indígenas têm jogado um papel chave tanto na criação e no reconhecimento do conceito de território como na intensificação das lutas identitárias que se desenvolvem em relação estreita com o território. Em outras palavras, os mapeamentos politizam profundamente a constituição da identidade indígena, o conceito de direitos territoriais e a relação entre essas duas esferas. Por outro lado, a luta por reconhecimento tem sido caracterizada por grupos hegemônicos como uma invenção arquitetada por entidades de apoio que visam angariar grandes extensões de terras públicas. Esse argumento procura obscurecer o fato de que a disputa política fundamental para esses grupos é a que se relaciona à garantia do acesso ao território, uma vez que, sem ele, se dilui a capacidade de manterem suas especificidades como grupo étnico. Portanto, a terra constitui o recurso fundamental para a garantia de sua reprodução física e cultural (ALMEIDA, 2005, p. 44).

Para além dos aspectos elencados até aqui, a luta pela apropriação dos territórios no conjunto de glebas Mamuru-Arapiuns teve desdobramentos no campo das representações cartográficas e deu origem a um movimento que se imbrica nas disputas territoriais. A próxima seção procura lançar luz sobre as representações cartográficas produzidas pelos grupos sociais envolvidos nessa peleja e objetiva salientar que, ao contrário do postulado por Harley (1995), em determinados contextos há a possibilidade de utilização contra-hegemônica dos aparatos e técnicas da cartografia.

2. Representações cartográficas e disputas territoriais no conjunto de glebas Mamuru-Arapiuns

Para muitos cartógrafos, um bom mapa é aquele que representa de maneira fidedigna a realidade natural, contudo, do ponto de vista sociológico, os mapas

5. A emergência desses novos sujeitos políticos foi verificada na Gleba Nova Olinda I, uma vez que as comunidades de Novo Lugar, Cachoeira do Maró e São José III se autorreconhecem como pertencentes ao povo indígena Borari e se aglutinam num combate pela garantia e defesa de seus territórios. 
fazem mais do que isso, uma vez que envolvem um processo de seleção, abstração e significação, e este cria acepções e simbologias acerca dos espaços, tornando-os legíveis e compreensíveis para determinados sujeitos sociais (VANDERGEEST, 1995). Na medida em que um mapa é construído e projetado com base em uma posição específica na estrutura social e em um lugar institucional próprio, sua confecção inclina-se à parcialidade de quem o produziu. Nesse sentido, a cartografia, conscientemente ou não, reproduz mais que o ambiente natural que é substrato de suas representações: ela instaura no território os imperativos de um sistema político (HARLEY, 1995). No contexto de disputa das glebas Mamuru-Arapiuns, torna-se necessário auscultar as diversas tramas subjacentes à construção dessas representações cartográficas que expressam diferentes interesses e visões, bem como indagar sobre as artimanhas políticas que se forjam e entretecem como resultado da realização dos mapas.

Em decorrência do decreto que instituiu a Alap no conjunto de glebas Mamuru-Arapiuns, teve início uma articulação entre movimentos sociais, ONGs, comunidades tradicionais e órgãos da administração pública federal e estadual, com a proposta de elaborar um mapa participativo para expressar as demandas territoriais das populações tradicionais. Como se pode evidenciar na transcrição abaixo, extraída de uma entrevista com um integrante do corpo técnico do Ibama, a aglutinação desses sujeitos teve como foco possibilitar a participação dos comunitários no processo de definição dos limites e das modalidades de destinação das terras; concomitantemente, buscava-se visibilizar e demarcar a luta empreendida por essas populações pela garantia de seus direitos territoriais.

O governo estabelece a Alap para tocar um processo de ordenamento e constitui um grupo de trabalho composto por Ideflor, Sema e Iterpa. Entendíamos que o processo deveria ser participativo para que os próprios comunitários pudessem definir as modalidades de destinação. Aí se articulou uma aproximação entre os movimentos sociais e as parcerias técnicas. Quem tocou esse processo foi o STTR/Santarém e a Comissão Pastoral da Terra. Nós do Ibama contribuímos com a elaboração de um aporte técnico e fizemos isso em conjunto com o Projeto Saúde e Alegria. As comunidades foram apontando no mapa quais os limites e os conflitos que eram vivenciados no território. Cada comunidade apontou sua terra de uso e nossa ideia era pensar a região como um todo. Eu percebia que na Nova Olinda I havia uma unidade de luta, apesar das especificidades de cada comunidade. Pensou-se em áreas para as comunidades e também em zonas para a conservação. Era uma garantia para a proteção dos recursos naturais. (Entrevista com representante do corpo técnico do Ibama - Santarém, 24 set. 2009.) 
Esse processo de aglutinação de forças foi facilitado pelo acúmulo de experiências advindas de dois projetos de mapeamentos participativos que haviam sido realizados na Gleba Nova Olinda I e no Projeto de Assentamento Lago Grande (área circunvizinha ao conjunto de glebas Mamuru-Arapiuns) ${ }^{6}$. Os antecedentes possibilitados por essas duas experiências de mapeamento, em conjunção com o trabalho de base efetuado pelos movimentos sociais da região, originaram um encontro preparatório, em Santarém, com a participação de lideranças comunitárias do conjunto de glebas Mamuru-Arapiuns, durante o qual se estabeleceram os passos necessários para a construção de um mapeamento participativo capaz de expressar as demandas comunitárias.

No âmbito desse encontro, foram apresentadas as modalidades de destinação das terras e distribuídos os mapas dos rios e igarapés que deveriam ser discutidos e trabalhados em cada comunidade, com vistas a fixar os limites da ocupação e as modalidades de preferência para a titulação das terras. Como desdobramento, as comunidades se reuniram novamente para a realização do Seminário de Elaboração Participativa de Mosaico de Uso da Terra na Alap Nova Olinda/Mamuru no Oeste do Pará7. Durante esse seminário, foram consolidadas as reivindicações de modalidades de destinação das terras e estabelecidos os limites territoriais entre as comunidades, ações que, posteriormente, deram origem ao documento Plano participativo de mosaico de usos da terra nas glebas: Nova Olinda I, II, III, Curumucuri e Mamuru no oeste do Pará. Essa proposta foi composta, dentre outras coisas, de um mapa, apresentado a seguir, que expressa cartograficamente as demandas territoriais das comunidades e cuja construção havia sido objeto da reunião preparatória, dos trabalhos conduzidos nas comunidades e do seminário supracitado. Assim, mostra-se o resultado da articulação entre comunidades, movimentos sociais e parcerias técnicas.

6. O trabalho foi conduzido pela ONG Projeto Saúde e Alegria em parceria com o STTR de Santarém e com financiamento da Fundação Ford.

7. $O$ evento contou com a participação de 51 comunidades, nove instituições e oito associações intercomunitárias representadas por 125 participantes de toda a Alap e zonas circunvizinhas - Reserva Extrativista Tapajós-Arapiuns, Lago Grande e Aveiro (STTR; CPT, 2008). 


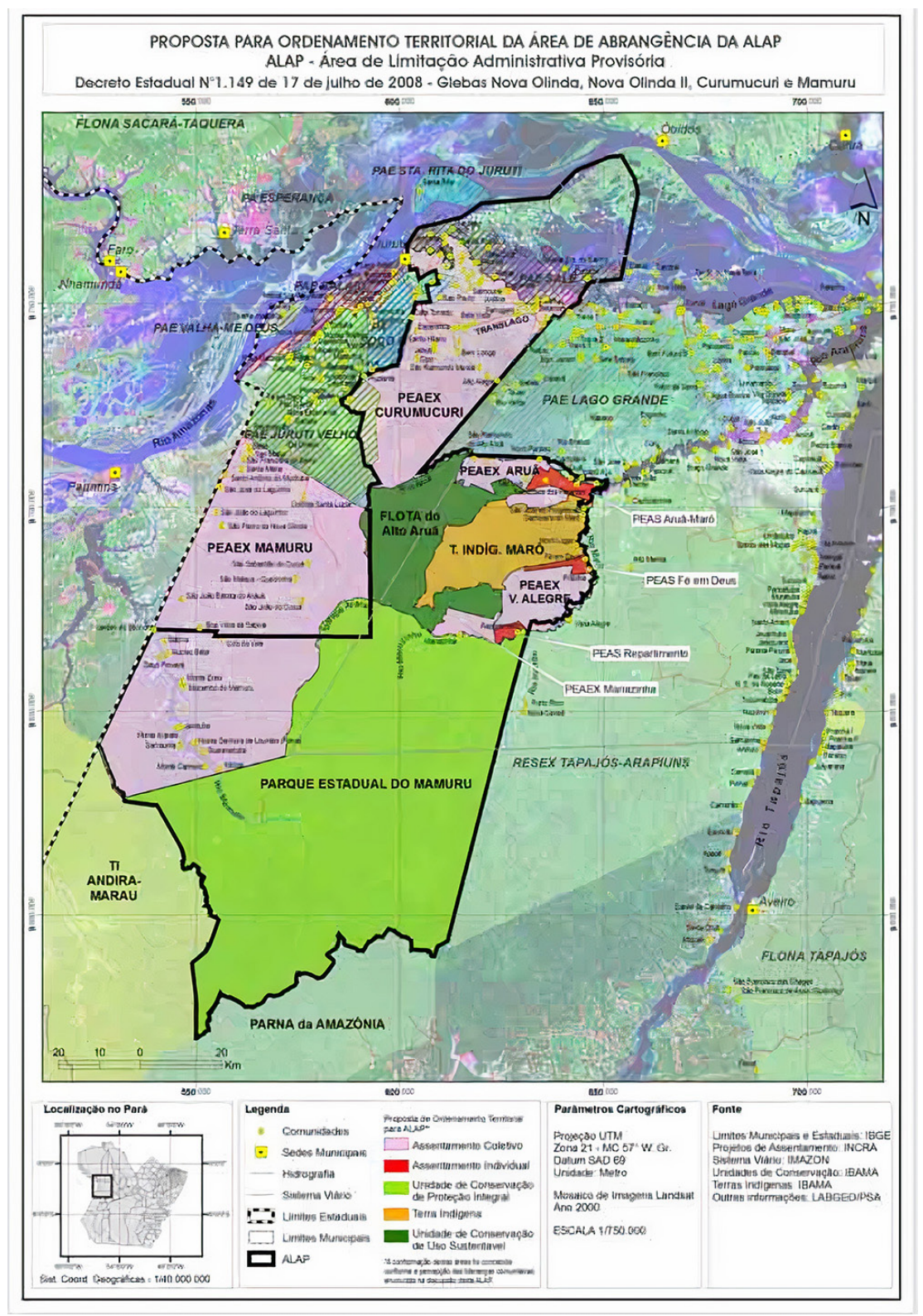

Mapa 1. Mapa-síntese da proposta das comunidades e movimentos sociais para ordenamento territorial da Alap.

Fonte: STTR de Santarém e CPT, 2008.

Com a elaboração desse mapeamento, comunidades e movimentos sociais se anteciparam às definições que vinham sendo arquitetadas no âmbito das esferas de governo e cartografaram suas territorialidades. A observação do Mapa 1 permite constatar a proposição de cinco Projetos Estaduais de Assentamento 
Agroextrativistas $^{8}$ (Peaex Curumucuri, Peaex Mamuru, Peaex Aruã, Peaex Vista Alegre e Peaex Mariazinha), três Projetos Estaduais de Assentamento Sustentável ${ }^{9}$ (Peas Repartimento, Peas Fé em Deus e Peas Aruã-Maró), bem como a constituição da Terra Indígena Maró e do Parque Estadual do Mamuru. Ademais, foram propostas a retirada dos permutados que ocupam áreas limítrofes às comunidades e a criação, no mesmo local, da Flota - Floresta Estadual do Alto-Aruã. Com exceção dos três Peas, que apresentam regime individual de apropriação das terras, essa representação cartográfica almeja realçar a existência de visões e modos distintos de utilização dos territórios. Nesse sentido, constitui-se na expressão de processos de valorização que ultrapassam a racionalidade econômica capitalista em seu intuito de atribuir preços e custos ao meio ambiente e atingem a mobilização de atores sociais em nome de interesses materiais e simbólicos (de sobrevivência, identidade, autonomia e qualidade de vida), que estão além das demandas estritamente econômicas de emprego e distribuição de renda (LEFF, 2001). Em um cenário de acirramento das disputas territoriais, as chamadas cartografias sociais e os mapeamentos participativos vêm se difundindo como um recurso crítico à despolitização que caracteriza as disparidades e assimetrias na apropriação dos recursos naturais (ALMEIDA, 1993).

As organizações, instituições e sujeitos sociais que se valem desse tipo de abordagem ressaltam a capacidade de controle dos recursos naturais, assim como seu potencial de aglutinação política ao redor de lutas pela garantia de direitos territoriais, contra deslocamentos compulsórios e pela defesa dos recursos naturais. Isso pode ser realçado e corroborado pelo discurso de lideranças comunitárias, representantes de ONGs e órgãos da administração púbica que colaboraram na elaboração do Mapa 1.

Os madeireiros chegaram e colocaram a gente pra pensar. Nós resolvemos fazer o mapa para descobrir onde estava o problema em nossas terras. Quando fazíamos as denúncias da presença dos madeireiros, era uma denúncia fria, não que não existisse o fato, mas

8. Os Peaexs se destinam a populações que ocupam áreas dotadas de riquezas extrativas e praticam prioritariamente a exploração sustentável dos recursos naturais voltadas para a reprodução social. A área é considerada de domínio público com uso concedido às populações, e a destinação é efetuada mediante uma concessão de direito real de uso, em regime de uso comum, associativo ou cooperativista por prazo indeterminado (ITERPA, 2009; STTR; CPT, 2008).

9. Os Peas abrangem as áreas trabalhadas em regime de economia familiar que utilizam racionalmente os recursos naturais existentes. A destinação das áreas ocorre por meio de um contrato de concessão de uso em regime individual, em nome da unidade familiar. Trata-se de um contrato intransferível e inegociável pelo prazo de dez anos, ao término do qual poderá ser transacionado no mercado de terras (ITERPA, 2009; STTR; CPT, 2008). Como vimos anteriormente, essas são comunidades onde já se consolidou uma presença efetiva dos madeireiros e grileiros em um ambiente de dependência e subserviência. 
não tínhamos os dados precisos de onde se localizavam (Entrevista com liderança indígena B. - Aldeia Novo Lugar, rio Maró, Santarém, 29 set. 2009).

Acho que os mapeamentos foram uma base para se ter inclusive a mobilização. Agora o comunitário tem ciência do que está ao seu redor. Uma apropriação no sentido técnico, penso que não houve, e essa é uma etapa que precisamos avançar no desenvolvimento local das comunidades. O limite maior é o conhecimento técnico. Tu tens que construir uma equipe técnica muito cara e que demanda tempo. Outro limite é que essa é uma ferramenta nas mãos da elite composta por universidade, ONGs, madeireiros, grileiros. A realização de mapeamentos participativos deveria ser uma política pública. (Entrevista com representante da ONG Projeto Saúde e Alegria - Santarém, 24 set. 2009).

Para Habegger e Mancila (2006), cartografias e mapeamentos participativos podem converter-se em catalisadores de processos de mudança, empoderar indivíduos, fortalecer comunidades, controlar espaços e liberar vozes previamente não escutadas. Resultam, portanto, em uma maneira de transformar mapas descritivo-analíticos em mapas propositivos de intervenção que encaminham estratégias coletivas de transformação social. Do mesmo modo, Baron e Colombia (2005), em pesquisa sobre cartografias sociais em contexto urbano, reconhecem a importância dos mapas na construção de sujeitos políticos e demonstram o poder que estes têm de ordenar o pensamento, gerar conhecimento coletivo e formar consciência e desejo de luta no interior de realidades históricas, adversas e conflitivas.

Embora essas potencialidades sejam identificadas em cartografias sociais e em mapeamentos participativos, alguns autores têm argumentado sobre a existência de dissimetrias no que se refere tanto ao domínio das tecnologias de informação empregadas na consecução dos mapas como à apropriação das cartografias resultantes da "participação" comunitária. Na visão de Joliveau (2008), os mapas são ferramentas potentes de desvendamento, cujo controle, contudo, exige uma especialização que não é igualmente compartilhada entre os distintos atores, ONGs, universidades, organismos multilaterais, comunidades; isso, por sua vez, acarreta efeitos de poder que representam problemas para a participação. Desse modo, ao se verter o saber forjado na cotidianidade, em que o pertencimento ao lugar orienta percursos e ancora relações sociais, para uma linguagem ortogonal atrelada a um sistema de informação geográfica, não dominado pelas populações e gerido por um corpo de especialistas, instaura-se um ambiente de desigualdade no comando e na apropriação do mapa. Ademais, é necessário considerar outras facetas dos mapeamentos participativos, inclusive, como expressão da ótica da ideologia do desenvolvimento. 
Na perspectiva de Acselrad (2009), a noção de mapeamento participativo surge, pois, com a marca dessa ambiguidade: construída para dar palavra às comunidades de base e a grupos desfavorecidos, sua realização mostra-se dependente da estrutura de poder na qual se instaura. No vasto espectro de experiências identificadas pelo autor, podem-se verificar experiências associadas à afirmação identitária e territorial de grupos subalternos, à fundamentação cognitiva da gestão racional de recursos naturais, às formas de explicitação de conflitos socioterritoriais ou de antecipação destes para fins de controle estatal do território. No que diz respeito à última modalidade, o trecho a seguir, extraído de uma entrevista com representantes do Estado, exemplifica uma das formas de utilização do mapeamento participativo no ordenamento territorial das glebas Mamuru-Arapiuns:

Na realidade, o trabalho que o Ideflor está fazendo vai exatamente em direção ao mapeamento participativo [...]. Pessoalmente acredito que essa é uma das melhores ferramentas para que o poder público, bom, primeiro a população local, lógico [risos], e o poder público, por consequência, tá?, possa ter informações mais detalhadas e possa, portanto, ter um conjunto de decisões que, nós sabemos, compete nesse caso à autoridade estadual assumir, mas a partir de um diálogo mais permanente, mais constante e que tem na sua origem uma discussão não só com alguns interlocutores, como normalmente é praxe, mas com a população local que tem a possibilidade efetiva de entender o espaço, pois, muitas vezes, minha experiência de trinta anos de assessor do movimento social mostra, nem sempre é fácil isso. (Entrevista com assessor-chefe da presidência do Iterpa, Belém, 16 set. 2009.)

Como se pode notar, os mapeamentos participativos têm a faculdade de assumir direções antípodas: de um lado, podem capturar o saber tradicional/ popular, propiciando o enquadramento econômico de práticas sociais e relações com o ambiente, e, de outro, como no caso do mapa elaborado pelos movimentos sociais, podem suscitar a insurgência comunitária, articulando o uso político da cartografia ao fortalecimento das lutas pela observância de direitos territoriais. Em estudo realizado no Sudeste Asiático, Colchester (2002) demonstra que uma das dificuldades dos mapeamentos participativos consiste na tendência de estabelecer demarcações estáticas para configurações territoriais que são instáveis e fluidas. Assim, a representação cartográfica acaba por traçar rígidas linhas delimitadoras, onde, na verdade, poderiam prevalecer fronteiras imprecisas e ambíguas. Com base nisso, pode-se conjecturar que a crescente adesão de comunidades tradicionais aos mapeamentos participativos e a cartografias sociais que utilizam tecnologias do 
tipo Sistemas de Informação Geográfica (SIG) pode afetar os modos particulares de visão e divisão do mundo, vindo a fortalecer a legitimidade de formas hegemônicas de representação (BOURDIEU, 1989).

Como reação ao mapa apresentado pelas comunidades tradicionais, outros sujeitos com pretensão de uso desse espaço geográfico construíram suas propostas de mapeamento com o intuito de influenciar as decisões governamentais e legitimar a ocupação de domínios ilegalmente obtidos.

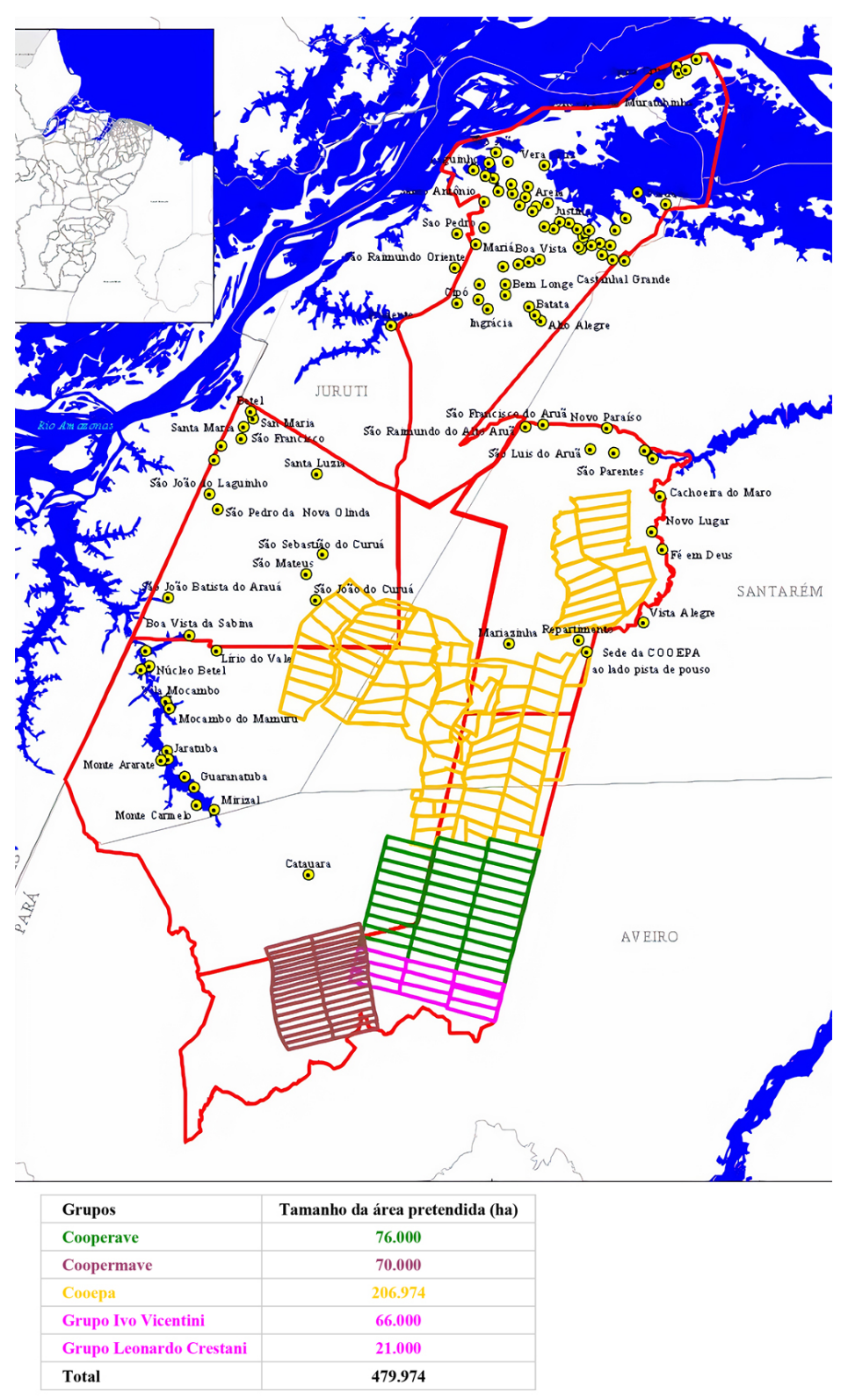

Mapa 2. Mapa-síntese das propostas das "cooperativas empresariais" para a Alap.

Fonte: Ideflor, com base em mapas e informações fornecidos pelas cooperativas que pleiteiam terras no conjunto de glebas Mamuru-Arapiuns, 2009. 
O Mapa 2, elaborado com base em informações de "cooperativas empresariais”, as quais têm executado um arrojado projeto de grilagem de terras no conjunto de glebas Mamuru-Arapiuns, pode ser visto como um mecanismo de representação cartográfica que cria uma imagem quimérica de retalhamento do território, ao mesmo tempo que imprime uma lógica de apropriação privada do espaço expressa por meio do desenho dos lotes. Nesse sentido, ao modo do mapa de John Mitchell, de 1755 (Map of British and French Dominions in North America), os grileiros representam as terras ocupadas por populações tradicionais como estando sob seus domínios, e isso forja uma abstração que faz frente às reais demandas territoriais das comunidades. Ele cria uma ideia de homogeneidade do território que, simultaneamente, favorece o avanço de formas hegemônicas de apropriação dos recursos ambientais e obscurece modos distintos de existência, os quais, embora situados em condições de subalternidade, constroem discursos e práticas opostos à expropriação perpetrada pela produção capitalista do espaço. Sobre esse aspecto, percebe-se que a cartografia "científica" se esforça para converter cultura em natureza e para naturalizar realidades sociais (HARLEY, 1989); dessa maneira, ao privilegiar uma sintaxe euclidiana, não deixa de contribuir para a modelagem dos comportamentos de poder vigentes nos territórios (RAFFESTIN, 1993).

Nessa mesma trilha, a imagem de satélite apresentada pelas entidades de classe que reúnem o segmento madeireiro (Figura 1) almeja edificar a ideia de um espaço vazio e ortogonal, passível, por sua vez, de ser racionalmente explorado. Nota-se que não há nenhuma referência ou representação das comunidades que tradicionalmente ocupam esse espaço; tampouco se conjectura a existência de áreas a serem destinadas à constituição de unidades de conservação. Essa imagem é uma abstração cartográfica que expressa uma racionalidade econômica de exploração dos territórios, com o propósito de corporificar e legitimar os interesses madeireiros e invisibilizar a existência de populações tradicionais. Assim, o texto da proposta que acompanha a imagem constrói a ideia de um espaço a ser apropriado pela produção capitalista de riquezas, em que a floresta é enxergada através de uma matriz de pensamento que releva o potencial de toras e metros cúbicos de madeira, as toneladas de óleos e essências, as cascas e os frutos que constituem o objeto de exploração. Nesse contexto, a representação de imensas áreas para concessão florestal, permutas, propriedade privada e construção de um centro de treinamento espelha a tentativa de transformar o conjunto de glebas Mamuru-Arapiuns em um novo polo de exploração madeireira. Por outro lado, embora haja áreas representadas como zonas de produção comunitária, a utilização 
das comunidades tradicionais é ressignificada com a atribuição a elas de um papel de parceria com as empresas, com sua consequente transformação em empreendedoras do negócio florestal.

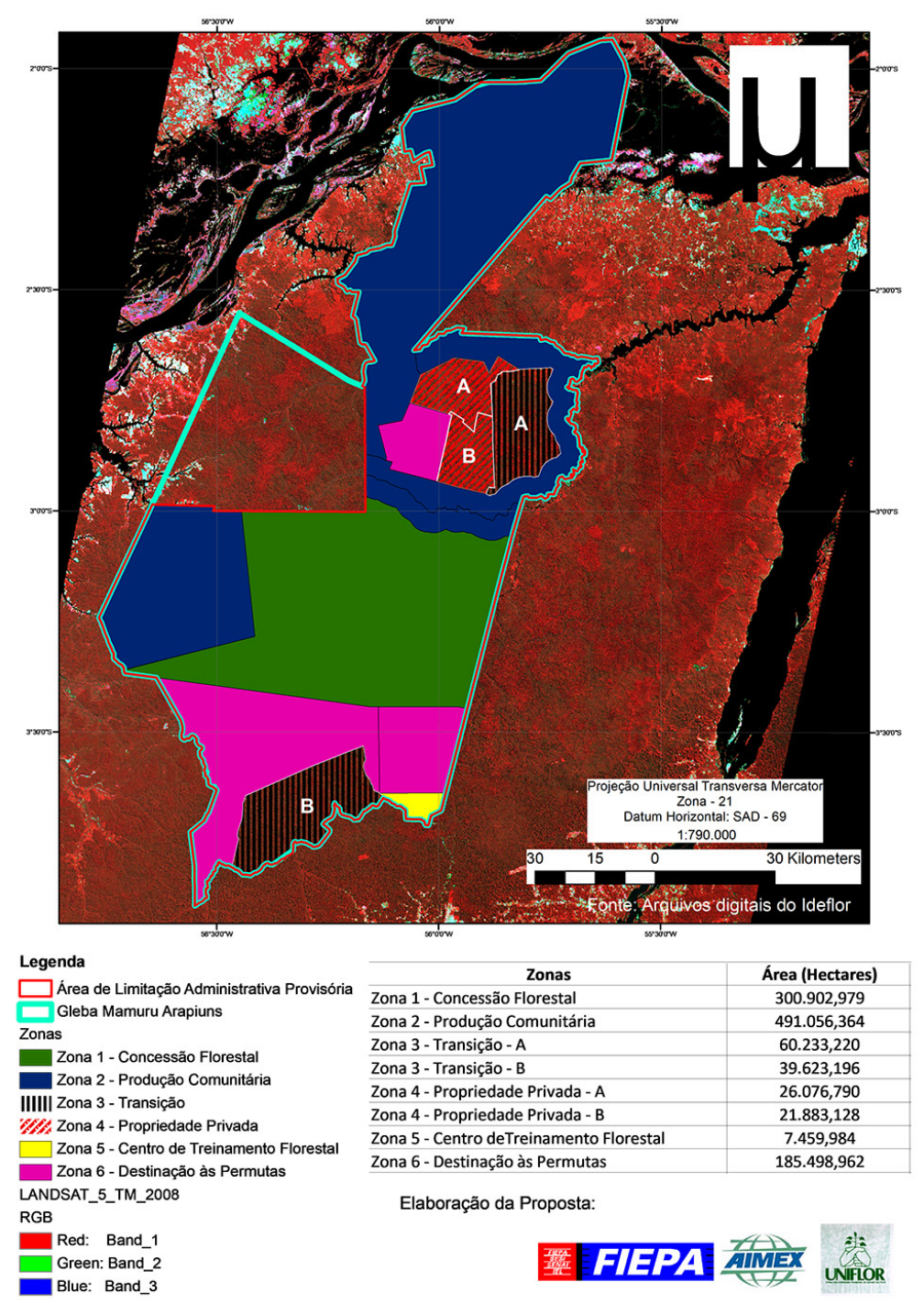

Figura 1. Imagem de satélite síntese das propostas do setor madeireiro para a Alap Fonte: Federação das Indústrias do Estado do Pará (Fiepa), 2009.

\section{Breve reflexão à guisa de conclusão}

Com base nos dois mapas e na imagem apresentados neste artigo, pode-se evidenciar que os conflitos prático-reais no que tange às atribuições e aos usos dos territórios se entrelaçam às disputas cartográficas que buscam hegemonizar certas representações. Além de indicar o embate entre distintas visões e formas 
de apropriação da natureza, esses mapas compõem um terreno em que o conflito se processa por meio da mescla de interesses e significados, orientados, por sua vez, pela forma como a natureza é utilizada material e simbolicamente. Assim, é possível notar nas representações cartográficas divergências entre tipos distintos de racionalidade - uma que se direciona a maximizar os benefícios comerciais provenientes do intercâmbio de mercadorias e outra que tende a maximizar as condições de reprodução social (LEFF, 1994).

Na visão de Harley (1995), diferentemente da literatura, da arte ou da música, a história dos mapas parece não comportar modos de expressão populares, alternativos ou subversivos, tendo em vista que os mapeamentos são essencialmente uma linguagem de poder, e não de contestação. Sem embargo, pode-se, com base nessa experiência do conjunto de glebas Mamuru-Arapiuns, sugerir a capacidade insurgente e contra-hegemônica da cartografia. Ainda que possa ser considerado um experimento isolado, que comporta uma série de incongruências e novos desafios, é evidente sua capacidade de luta, de aglutinação e de reivindicação por demarcação, conquista e manutenção de territórios

Outra particularidade diz respeito ao fato de os sujeitos "cartografantes" aqui analisados mapearem seus territórios ao mesmo tempo que mapeiam as posições ocupadas por seus adversários. Isso imprime um conteúdo propositivo que vai além do "ou mapeias ou te mapeiam” sugerido por Offen (2009), em que a realização dos mapeamentos representaria mais uma postura alinhada à atitude de resistência, que cartografa o próprio território, antes que outros o façam, mas que não se preocupa em localizar as posições hostis daqueles com os quais eles são disputados. Ao contrário, o caso aqui analisado se aproxima mais daquilo que se poderia denominar "me mapeio e te mapeio", uma vez que os sujeitos subalternizados constroem representações que visibilizam sua presença no território, além de criarem identificações e ressignificações dos espaços ocupados por aqueles que ameaçam sua reprodução social. Assim, considerando o embate cartográfico como desdobramento de lutas territoriais concretas, pode-se afirmar que ambos os lados incessantemente tratam de indagar as debilidades do outro e aproveitar qualquer mínima vantagem estratégica.

\section{Referências}

ACSELRAD, H. Mapeamentos, identidades e territórios. In: $33^{\circ}$ Encontro Anual da Associação Nacional de Pós-graduação e Pesquisa em Ciências Sociais, 2009 [Caxambu, MG].

Mapeamentos e tramas territoriais. In: Povos e comunidades tradicionais: nova cartografia social. Uema: Manaus, 2013. Disponível em: http://www.ppgcspa.uema.br/ wp-content/uploads/2015/07/Catalogo-Povos-Comunidades-Tradicionais-1.pdf. Acesso em: 14 out. 2019. 
ACSELRAD, H.; COLI, L. R. Disputas territoriais e disputas cartográficas. In: ACSELRAD, H. (org.). Cartografias sociais e territórios. Rio de Janeiro: Ippur/Universidade Federal do Rio de Janeiro, 2008.

ALMEIDA, A. W. B. de. Terras de preto, terras de santo e terras de índio: posse comunal e conflito. Revista Humanidades, Brasília: UnB, n. 15, p. 42-48, 1988.

. Carajás: a guerra dos mapas, repertório de fontes documentais e comentários para apoiar a leitura do mapa temático do seminário-consulta "Carajás: desenvolvimento ou destruição?”. Belém: Falangola, 1993.

- Nas bordas da política étnica: Os quilombos e as políticas sociais. Boletim Informativo do Nuer, Florianópolis, v. 2, n. 2, p. 15-44, 2005.

. Terra e territórios. A dimensão étnica e ambiental dos conflitos agrários. In: CANUTO, A.; LUZ, C. R. da S.; AFONSO, J. B. G.; SANTOS, M. M. (Org.). Conflitos no campo, Goiânia: CPT Nacional Brasil, v. 1, p. 16-41, 2006.

Mapas situacionais e categorias de identidade na Amazônia. In: Povos e comunidades tradicionais: nova cartografia social. UEMA: Manaus, 2013. Disponível em: http:// www.ppgcspa.uema.br/wp-content/uploads/2015/07/Catalogo-Povos-Comunidades-Tradicionais-1.pdf. Acesso em: 14 out. 2019.

AUGE, M. Não lugares: introdução a uma antropologia da supermodernidade. Campinas: Papirus, 1994.

BARON, C. G.; COLOMBIA, E. Barrios del mundo: historias urbanas - la cartografía social... pistas para seguir. In: Primer Encuentro Internacional Barrios Del Mundo, 2005. Disponível em: http://www.extension.unc.edu.ar/garciabaron_colombia.pdf. Acesso em: 21 out. 2009.

BELÉM (PA). Quarto Ofício de Notas de Bélem. Escritura pública de permuta e outras avenças. Fls. 267-269 do livro 156, ato 51. Belém, 2006.

BOURDIEU, P. O poder simbólico. Rio de Janeiro: Bertrand Brasil, 1989.

BRASIL. Decreto-lei n. 11.284, de 2 de março de 2006. Diário Oficial da União, 03/03/2006, p. 1. Disponível em: http://www.planalto.gov.br/ccivil_03/_Ato2004-2006/2006/Lei/L11284. htm. Acesso em: 18 out. 2009.

COLCHESTER, M. O mapeamento como ferramenta para garantir o controle comunitário: alguns ensinamentos do Sudeste Asiático. WRM, Boletim 63, out. 2002. Disponívelem https:// wrm.org.uy/pt/artigos-do-boletim-do-wrm/seca01/o-mapeamento-como-ferramenta-para-garantir-o-controle-comunitario-alguns-ensinamentos-do-sudeste-asiatico/. Acesso em 14 out. 2015.

COMISSÃO ESTADUAL DE FLORESTAS (COMEF). Relatório de visita às glebas estaduais da região Mamuru-Arapiuns - $2^{a}$ Expedição. Belém, 2009.

DEPARTAMENTO NACIONAL DE PROPRIEDADE MINERAL (DNPM). Pesquisa de Processo Módulo Administrativo, 2009. Disponível em: https://sistemas.dnpm.gov.br/SCM/extra/site/ admin/pesquisarProcessos.aspx. Acesso em: 29. out. 2009. 
EDNEY, M. H. A história da publicação do mapa da América do Norte de John Mitchell de 1755. Varia História, Belo Horizonte, v. 23, n. 37, p. 30-50, jan. 2007.

FOX, J.; SURIANATA, K.; HERSHOK, P.; PRAMONO, A. H. O poder de mapear: efeitos paradoxais das tecnologias de informação especial. In: ACSELRAD, H. (Org.). Cartografias sociais e territórios. Rio de Janeiro: Ippur/Universidade Federal do Rio de Janeiro, 2008.

HABEGGER, S.; MANCILA, I. El poder de la cartografía social en las prácticas contrahegemónicas o La Cartografía Social como estrategia para diagnosticar nuestro territorio, 2006. Disponível em: http://areaciega.net/index.php/plain/Cartografias/car_tac/el-poder-de-la-cartografia-social. Acesso em: 24 out. 2009.

HARLEY, J. B. Deconstructing the map. Cartographica, n. 26, p. 1-20, 1989.

Cartes, savoir et pouvoir. In: GOULD, P.; BAILLY, A. Le Pouvoir des cartes: Brian Harley et la cartographie. Paris: Ecomomica, 1995.

INSTITUTO BRASILEIRO DE MEIO AMBIENTE E DOS RECURSOS NATURAIS RENOVÁVEIS (IBAMA). Relatório técnico de vistoria da Gleba Nova Olinda. Santarém, 2007.

INSTITUTO DE DESENVOLVIMENTO FLORESTAL DO ESTADO DO PARÁ (IDEFLOR). Plano anual de outorga florestal 2008/2009, 2008. Disponível em: https://www.ideflor.pa.gov. br/index. php?q=node/72. Acesso em: 22 out. 2009.

INSTITUTO DE DESENVOLVIMENTO FLORESTAL E DA BIODIVERSIDADE DO ESTADO DO PARÁ (IDEFLOR-BIO). Balanço de Gestão 2011 a 2014 com ênfase no exercício de 2014, 2015. Disponível em https://ideflorbio.pa.gov.br/wp-content/uploads/2015/og/RELAT\%C3\%93RIO-de-GEST\%CC3\%83O-2014-vers\%C3\%A30-final-NAE-editado.pdf. Acesso em: 31 maio 2020.

INSTITUTO DE TERRAS DO PARÁ (ITERPA). O potencial florestal dos novos marcos de gestão pública, comunitária e privada no Oeste paraense: regularização fundiária da região Mamuru-Arapiuns. Seminário Ideflor: Santarém, 2009.

JOLIVEAU, T. O lugar do mapa nas abordagens participativas. In: ACSELRAD, H. (Org.). Cartografias sociais e territórios. Rio de Janeiro: Ippur/Universidade Federal do Rio de Janeiro, 2008.

KLEMPERER, V. LTI: A linguagem do Terceiro Reich. Tradução Miriam Bettina e Paulina Oelsner. Rio de Janeiro: Contraponto, 2009.

LEFF, E. Ecologia y capital: racionalidad ambiental, democracia participativa y desarrollo sustentable. México: Siglo Veintiuno, 1994.

. Saber ambiental: sustentabilidade, racionalidade, complexidade, poder. Petrópolis: Vozes, 2001.

MARTINS, J. de S. Fronteira: a degradação do outro nos confins do humano. São Paulo: Hucitec, 1997.

MASSEY, D. B. Pelo espaço: uma nova política da espacialidade. Rio de Janeiro: Bertrand Brasil, 2008.

OFFEN, K. O mapeas o te mapean: mapeo indígena y negro en América Latina. Tabula Rasa, Bogotá, 10, p. 163-189, 2009. 
OLIVEIRA FILHO, J. P. de. Indigenismo e territorialização: poderes, rotinas e saberes coloniais no Brasil contemporâneo. Rio de Janeiro: Contra Capa, 1998.

Soberania, democracia e cidadania. In: ALMEIDA, A. W. B. de; Farias JR., E. de A. (Org.) Povos e comunidades tradicionais: nova cartografia social. Uema: Manaus, 2013. Disponível em: http://www.ppgcspa.uema.br/wp-content/uploads/2015/07/Catalogo-Povos-Comunidades-Tradicionais-1.pdf. Acesso em: 14 out. 2019.

PEDLEY, M. S. O comércio de mapas na França e na Grã-Bretanha durante o século XVIII. Varia História, Belo Horizonte, v. 23, n. 37, p. 15-29, jan. 2007.

RAFFESTIN, C. Por uma geografia do poder. São Paulo: Ática, 1993.

SAUER, S.; MARTINS, P. S. V. Cultivo da soja e conflitos por terra na região de Santarém (Pará). In: VAN SOLINGE, T. B.; SAUER, S; VÉLEZ-TORRES, I.; VARGAS-VAN DEN BRINK, B. B. (Eds.) Terra e direitos em águas turbulentas: Conflitos socioambientais no Brasil e na Colômbia. Utrecht: Utrecht University, 2016.

SILVA, C. de C. do S.; MELO JÚNIOR, L. C. M. Gestão ambiental e sustentabilidade: Um estudo sobre os contratos de concessão florestal no estado do Pará. In: Anais do VI Seminário Estadual de Águas e Florestas, Belém, 2018.

SINDICATO DOS TRABALHADORES E TRABALHADORAS RURAIS DE SANTARÉM (STTR); COMISSÃO PASTORAL DA TERRA (CPT). Plano participativo de mosaico de uso da terra nas glebas: Nova Olinda I, II e III, Curumucuri e Mamuru no oeste do Pará. Santarém, 2008.

VANDERGEEST, P. Mapping Resource Claims: (or the Seductive Appeal of Maps). The Use of Maps in the Transformation of Resource Tenure. Meeting of the Association for the Study of Common Property. Ontario: mimeo. 1995.

WALLERSTEIN, I. M. The Modern World-System I: Capitalist Agriculture and the Origins of the European World-Economy in the Sixteenth Century. New York: Academic Press, 1974 . 


\section{Wendell Ficher Teixeira Assis}

Doutor em Planejamento Urbano e Regional. Professor adjunto do Instituto de Ciências Sociais da Universidade Federal de Alagoas. Pesquisador associado do Ettern - Laboratório Estado, Trabalho, Território e Natureza do Instituto de Pesquisa e Planejamento Urbano e Regional - Ippur/UFRJ.

Email:wwficher@yahoo.com.br

ORCID: 0000-0002-9711-0884

Submissão: 17 de dezembro de 2019.

Aprovação: 30 de abril de 2020.

Como citar: ASSIS, W. F. T. Pode o subalterno mapear e incidir no planejamento regional? Conflitos territoriais e disputas cartográficas no ordenamento fundiário do oeste do Pará. Revista brasileira de estudos urbanos e regionais. v. 22, E202017, 2020. DOI 10.22296/2317-1529.rbeur.202017

Artigo licenciado sob Licença Creative Commons CC BY-NC 4.0.

https://creativecommons.org/licenses/by-nc/4.o/deed.pt_BR 